\title{
ENTERIC PARASITIC INFECTIONS AMONG SCHOOL CHILDREN AT RUPANDEHI, NEPAL
}

\author{
Rita Khanal ${ }^{1}$, Sweety Upadhaya ${ }^{1}$, Pramila Lamichhane ${ }^{2,}$ Subash Lal Karn ${ }^{2}$, Sandeep Pokhrel ${ }^{2,}$ V.K Pahwa
}

\begin{abstract}
\section{INTRODUCTION}

Soil-transmitted helminths (STHs), are the common intestinal parasites among school age children in Nepal. Periodic epidemiological studies and transmission dynamics in parasitic infections will provide accurate understanding. The aim of this study is to find out the prevalence of intestinal parasitic infections among primary school children at Rupandehi district Nepal.
\end{abstract}

\section{MATERIALS AND METHODS}

This is a school based cross-sectional descriptive study including 217 students studying at primary level in two Government School in Rupandehi. The demographic data and anthropometric data was collected. Routine Stool examination was done and concentration techniques were used for maximum recovery of parasites.

\section{RESULTS}

The prevalence of parasitic infection was 60\% (130/217). Statistically significant association was found between parasitic infection and source of drinking water $(\mathrm{p}<0.05)$. A lumbricoides was most common followed by Taenia spp, Hymenolepsis nana and others. Parasitic infection was highest 70\% (21/30) in age group 13-15 years and lowest i.e. $38.1 \%(8 / 21)$ in age group 4-6 years. The mean height and weight of children was found to be $1.28 \mathrm{~m}$ and $26.5 \mathrm{~kg}$ respectively. Among total children $90.8 \%$ (197/217) of the children were malnourished $\left(\mathrm{BMI}<18.5 \mathrm{~kg} / \mathrm{m}^{2}\right)$ and among infected children $90 \%(117 / 130)$ were malnourished.

\section{CONCLUSION}

The intestinal parasitosis was found comparatively higher in school children in this region. Higher rate of infection was found in malnourished children.

KEYWORDS: Intestinal parasite, Malnutrition, School children, Soil transmitted helminthes, Nepal

1. Asst. Professor, Department of Microbiology, Universal College of Medical Sciences, Bhairahawa, Nepal

2. Lecturer, Department of Microbiology, Universal College of Medical Sciences, Bhairahawa, Nepal

3. Professor, Department of Microbiology, Universal College of Medical Sciences, Bhairahawa, Nepal

\author{
For correspondence: \\ Mrs. Rita Khanal \\ Asst. Professor \\ Department of Microbiology, \\ Universal College of Medical Sciences, \\ Bhairahawa, Nepal. \\ E-mail: ritakhanal@gmail.com \\ Mobile+9779867188819
}




\section{INTRODUCTION}

Intestinal parasitosis is one of the major public health problems, particularly in the developing countries like Nepal ${ }^{1}$. Ascaris lumbricoides, Trichuris trichura and hookworms (Necator americanus and Ancylostoma duodenale) collectively referred to as soil-transmitted helminths (STHs), are the common intestinal parasites among school age children in $\mathrm{Nepal}^{2,3,4}$. More than 1.5 billion people, or $24 \%$ of the world's population, are infected with soil-transmitted helminthic infections worldwide and over 600 million schoolage children live in areas where these parasites are intensively transmitted. ${ }^{5}$ In Nepal intestinal worm infection ranks sixth in top-ten diseases ${ }^{6}$ leading to anemia and other debilitating conditions, impaired learning, poor performance and absences from school among school children.

Parasitic infections such as STHs cause anorexia and poor absorption of nutrients and promote the deviation of nutrients to organism's defence mechanism, thereby contributing to onset of exacerbation of weight and height deficits and as well as specific nutritional deficiencies ${ }^{7}$. Infection and prevalence of the various intestinal parasites species has principally been ascribed to the inappropriate sanitary habit, absence of safe and pure drinking water, unmanaged faecal disposal system, poor socioeconomic condition and wide distribution of parasites contained in the environment ${ }^{8,9}$. So periodic epidemiological studies and transmission dynamics in parasitic infections will provide more accurate understanding ${ }^{10}$. Therefore this study was conducted with the aim to find out the prevalence of intestinal parasitic infections among primary school children at Rupandehi district, Nepal.

\section{MATERIALS AND METHODS}

This school based cross-sectional descriptive study was conducted during the month of March to September 2015. A total of 217 students studying at primary level in two different Government Schools in Rupandehi, were enrolled as study population. Children taking anti-helminthic drugs within the period of six months were excluded from the study. Informed consent from the Principal of the school was taken. Students were instructed to collect stool samples in provided clean, wide mouthed, screw capped dry plastic containers. Demographic data and data regarding predisposing factors were collected using a structured questionnaire at time of sample collection. Collected sample was mixed with $10 \%$ formalin solution and transported to Microbiology Laboratory of Universal College of Medical Sciences (UCMS), Bhairahawa, Nepal. The faecal specimens were examined by preparing direct smears with normal saline and iodine along with concentration methods employing both formal-ether sedimentation technique and common salt floatation technique for maximum recovery of parasites. The findings obtained from all these three methods for each sample were noted. Data was analysed using SPSS version 16.
Body mass index $(\mathrm{kg} / \mathrm{m} 2)$ was calculated from measurements of weight $(\mathrm{kg})$ and the height $(\mathrm{m})$ obtained. Height and weight measurements were recorded to nearest $0.1 \mathrm{~cm}$ and $0.5 \mathrm{~kg}$ respectively. The BMI was computed following the standard formula: $\mathrm{BMI}=$ Weight $(\mathrm{kg}) /$ Height $\left(\mathrm{m}^{2}\right)$. BMI for age was used to evaluate the nutritional status of the children above 5 years and adolescence ${ }^{11}$.

\section{RESULTS}

The prevalence of parasitic infection was $60 \%(130 / 217)$ in which $59.3 \%$ (54/91) were boys and $60.3 \%$ (76/126) were girls. The association of intestinal parasitosis with different factors like gastrointestinal (GI) symptoms, hygienic habits and family size etc. is given in Table 1 . Statistically significant association was found between parasitic infection and source of drinking water $(\mathrm{p}<0.05)$.

Table 1: Prevalence of intestinal parasites with different risk factors among the students

\begin{tabular}{|c|c|c|c|}
\hline Categories & Total & Positive (\%) & p-value \\
\hline \multicolumn{4}{|c|}{ Gastrointestinal symptoms } \\
\hline Yes & 30 & $22(73.3)$ & \multirow[t]{2}{*}{$\mathrm{p}>0.05$} \\
\hline No & 187 & $108(57.7)$ & \\
\hline \multicolumn{4}{|c|}{ Source of drinking water } \\
\hline Boring & 71 & $39(55)$ & \multirow{3}{*}{$\mathrm{p}<0.05$} \\
\hline Tube Well & 136 & $81(59.5)$ & \\
\hline Piped Water & 10 & $10(100)$ & \\
\hline \multicolumn{4}{|l|}{ Use Of Toilet } \\
\hline Yes & 169 & $105(62.1)$ & \multirow[t]{2}{*}{$\mathrm{p}>0.05$} \\
\hline No & 48 & $25(52.1)$ & \\
\hline \multicolumn{4}{|c|}{ Hand Washing Before Meal } \\
\hline Water & 75 & $47(62.7)$ & \multirow{2}{*}{$p>0.05$} \\
\hline Soap and water & 142 & $83(58.4)$ & \\
\hline \multicolumn{4}{|c|}{ Hand Washing After Toilet } \\
\hline Water & 11 & $7(63.6)$ & \multirow[t]{2}{*}{$\mathrm{p}>0.05$} \\
\hline Soap and water & 206 & $123(59.7)$ & \\
\hline \multicolumn{4}{|c|}{ Walking Bare Foot } \\
\hline Yes & 45 & $25(55.5)$ & \multirow[t]{2}{*}{$\mathrm{p}>0.05$} \\
\hline No & 172 & $105(61)$ & \\
\hline \multicolumn{4}{|c|}{ No of family members } \\
\hline$s$ & 98 & $59(60.2)$ & \multirow[t]{2}{*}{$\mathrm{p}>0.05$} \\
\hline$>5$ & 119 & $71(59.7)$ & \\
\hline \multicolumn{4}{|c|}{ Rearing of domestic animal } \\
\hline Yes & 146 & $85(58.2)$ & \multirow[t]{2}{*}{$p>0.05$} \\
\hline No & 71 & $45(63.3)$ & \\
\hline
\end{tabular}

Out of infected children $89.2 \%(116 / 130)$ children had single parasitic infection while mixed infection was found in $10.8 \%$ (14/130). A. lumbricoides was most common followed by 
Taenia spp, Hymenolepsis nana and others as shown in Table 2.

\section{Table 2: Frequency of parasites}

\begin{tabular}{|l|l|}
\hline Parasites & No. of positive samples \\
\hline \multicolumn{1}{|c|}{ Ascaris lumbricoides } & 105 \\
\hline Ascaris lumbricoides + Trichuris trichura & 2 \\
\hline Ascaris lumbricoides + Hymenolepis nana & 10 \\
\hline Ascaris lumbricoides + Schistosoma spp & 1 \\
\hline Ascaris lumbricoides + Ancyclostoma spp & 1 \\
\hline Taenia spp. & 3 \\
\hline Enterobius vermicularis & 2 \\
\hline Hymenolepis nana & 2 \\
\hline Trichuris trichura & 2 \\
\hline Giardia lamblia & 1 \\
\hline Entamoeba histolytica & 1 \\
\hline Total & 130 \\
\hline
\end{tabular}

The occurrence of parasitic infection was highest $70 \%(21 / 30)$ in age group 13-15 years and lowest i.e. $38.1 \%(8 / 21)$ in age group 4-6 years as shown in table 3 .

\section{Table 3: Parasitic infections in different age groups}

\begin{tabular}{|l|l|l|l|}
\hline Age group (years) & Total number (n) & Positive (\%) & p-value \\
\hline $4-6$ & 21 & $8(38.1)$ & \\
\cline { 1 - 3 } $7-9$ & 60 & $36(60)$ & \multirow{2}{*}{$>0.05$} \\
\cline { 1 - 3 } $10-12$ & 106 & $65(61.3)$ & \\
\cline { 1 - 3 } $13-15$ & 30 & $21(70)$ & \\
\cline { 1 - 3 } Total & 217 & $130(60)$ & \\
\cline { 1 - 3 } & & & \\
\end{tabular}

The profile of anthropometric measurements of children is shown in Table 4.The mean height and weight of children was found to be $1.28 \mathrm{~m}$ and $26.5 \mathrm{~kg}$ respectively. Among total children $90.8 \%(197 / 217)$ of the children were malnourished $\left(\mathrm{BMI}<18.5 \mathrm{~kg} / \mathrm{m}^{2}\right)$ and among infected children $90 \%$ (117/130) were malnourished.

Table 4: Profile of anthropometric measurements among children

\begin{tabular}{|l|l|l|}
\hline Body Mass Index $\left(\mathbf{k g} / \mathbf{m}^{\mathbf{2}}\right)$ & Malnourishment status & Total \\
\hline$<16$ & Severely & 118 \\
\hline $16-16.9$ & Moderate & 50 \\
\hline $17-18.4$ & Mild & 29 \\
\hline $18.5-25$ & Normal & 16 \\
\hline$>25$ & Obese & 4 \\
\hline Total & & 217 \\
\hline
\end{tabular}

Figure 1 shows that among the infected children 52\%(68/130) were severely malnourished.

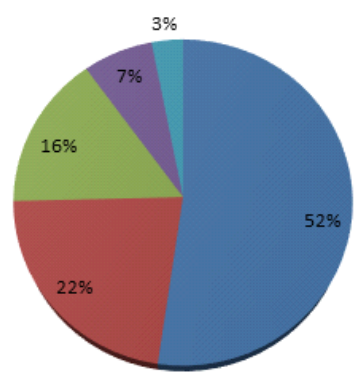

- Severely

- Moderate

Inild

- Normal

- Obese

Figure: 1. Distribution of infected children with malnutrition status

\section{DISCUSSION}

Intestinal parasitic infection has been a serious medical and public health problem in the world, especially in the developing countries like Nepal. This small scale study found the prevalence of parasitic infection to be $60 \%$ which is lower than the prevalence among the school going children in three districts namely Parsa, Surkhet and Dailekh ${ }^{12}$. Different other studies have reported lower prevalence rate of $15 \%$ in Pokhara $^{13}, 16.7 \%$ in Lalitpur ${ }^{14}, 17.6 \%$ in Kathmandu ${ }^{15}$ and $31.1 \%$ in Dadeldhura ${ }^{16}$. These differences could be due to geographical settings, socio-economic conditions, cultural practices, awareness programmes, availability of clean drinking water, economical and inhabitant customs etc.

The gender wise prevalence seems almost equal among boys and girls. Gender independence of intestinal worm infestation has been reported by others ${ }^{17,18}$. However, higher infection rate in girls has been shown by Khadka et $\mathrm{al}^{13}$; Sherchan et $\mathrm{al}^{19}$, while Ishiyama et $\mathrm{al}^{20}$, and ThapaMagar et $\mathrm{al}^{4}$, reported higher rate of infection in males. This indicated that the association of gender with parasitic infection differs from one community to another and might be attributed to socio-behavioural activities. Children drinking water from well and boring had lower prevalence rate than those drinking piped water and the result was in consistent with other studies. ${ }^{4,1}$ This necessitates the protection of water sources from faecal contamination and correction of water supply system.

Among various parasites detected A. lumbricoides was most common. Similar finding has been reported by Bhandari et al ${ }^{21}$, Amara et al ${ }^{22}$. However, Khanal et al ${ }^{15}$ reported T. trichura while Khadka et $\mathrm{al}^{13}$, Tandukar et $\mathrm{al}^{14}$, reported Giardia lamblia the most common. Shrestha et $\mathrm{al}^{23}$ reported E. histolytica as the predominant one and Tiwari et $\mathrm{al}^{16}$ reported $\mathrm{H}$ nana as the most predominant one. This difference may be due to the difference in environment of area selected for research, time of research and socioeconomic condition of parents and children that are selected for research purpose. 
Intestinal parasitic infection was found to be highest among children aged 13-15 years and lowest in age group 4-6 years. This was in accordance with Tandukar et $\mathrm{al}^{14}$ and Shrestha et al ${ }^{23}$. Low infection rate among small school children may be due to direct observation of their parents whereas grown up school children are in their transition phase and are seldom under the control of their parents regarding dietary habits, usually lack the education regarding healthy dietary habits and engagement of this age group child in different types of games in polluted environment. Also children of higher age group are fascinated towards street food and drinks which may be important predisposing factors for high prevalence of parasitic infection in this age group. However, this is in contrast to Khanal et al ${ }^{15}$, Tiwari et al ${ }^{16}$, Sharma et al ${ }^{8}$, who found infection rate highest in children aged 4-8 and lower in higher age group.

The recovery of eggs of A. lumbricoides, E. vermicularis and $H$. nana was better by formal ether sedimentation methods than by other technique. Slightly better recovery of Ascaris eggs, Enterobius vermicularis ova with sedimentation procedures has also been reported by Faraj et al. ${ }^{24}$

Parasitic infections have been shown to have deleterious effects on host nutritional status. The relationship of malnutrition and intestinal parasitic infection has been well established. ${ }^{25,26}$ However, the high prevalence of malnutrition in infected children could be that parasitic infection contributes to child under-nutrition through subtle reduction in digestion and absorption, chronic inflammation and loss of nutrients contributing to the onset or exacerbation of weight and height deficits, as well as to specific nutritional deficiencies that leads to nutritional deficiencies. ${ }^{7}$ In turn under-nutrition can make person more susceptible to parasitic diseases. However malnutrition observed among non-infected children may be due to inadequate food intake as well as their socioeconomic status.

\section{CONCLUSION}

The intestinal parasitosis was found comparatively higher among the school children in this region. Higher rate of infection was found in malnourished children. Therefore, it indicates that there is a need for comprehensive program to combat intestinal parasites associated with morbidity and mortality among children in Nepal.

\section{ACKNOWLEDGEMENT:}

We would like to acknowledge the students and teachers for their unfailing cooperation and participation during the survey.

\section{REFERENCES}

1. http://www.who.int/whosis/whostat/EN_WHS10_Full.pdf

2. Rai SK, Gurung R, Saiju R, Bajracharya L, Rai N, Gurung K, et al. Intestinal parasitosis among subjects undergoing cataract surgery at the eye camps in rural hilly areas of Nepal. Nepal Med Coll J 2008;10(2): 100103

3. Marothi Y, Singh B. Prevalence of intestinal parasites at Ujjain, Madhya Pradesh, India: five-year study. Afr J Microbiol Res 2011;5(18): 27112714

4. ThapaMagar D, Rai SK, Lekhak B, Rai KR. Study of parasitic infection among children of Sukumbasi Basti in Kathmandu valley. Nepal Med Coll J 2011;13(1):710.

5. Montresor A, Crompton DWT, Gyorkos TW, Savioli L. Helminth control in school age children. A guide for managers of control programmes. WHO Report, Geneva 2002; 1-27.

6. Fact sheet of Ministry of Health and Population. Government of Nepal MoHP 2010.

7. Administrative Committee on Coordination/Sub Committee on Nutrition News United Nations (ACC/SCN): $3^{\text {rd }}$ Report on the World Nutrition Situation. Geneva: ACC/SCN; 1997

8. Sharma BK, Rai SK, Rai DR, Choudhary DR. Prevalence of intestinal parasitic infestation in school children in the northeastern part of Kathmandu Valley, Nepal. Southeast Asian J Trop Med Public Health 2004;35: 501505

9. Gyawali N, Amatya R, Nepal HP. Intestinal Parasitosis in School going children of Dharan Municipality, Nepal. Trop Gastroenterol 2009; 30:145-147.

10. WHO, World Health Report, Controlling disease due to helminthes infections. 2008.

11. Cole TJ, Flegal KM, Nicholls D, Jackson AA. Body mass index cut offs to define thinness in children and adolescents: International survey. BMJ 2007;335(7612): 194.

12. Department of health sciences (Kathmandu). Annual report: Department of Health science. FY 2059/60 (2002/2003).

13. Khadka KS, Kaphle HP, Gurung K, Shah Y, Sigdel M. Study of Intestinal parasitosis among school going children in Pokhara, Nepal. JHAS 2013; 3(1): 47-50.

14. Tandukar S, Ansari S, Adhikari N, Shrestha A, Gautam J, Sharma B, et al. Intestinal parasitosis in school children of Lalitpur district of Nepal. BMCRes Notes 2013;6: 449.

15. Khanal LK, Choudhury DR, Rai SK, Sapkota J, Barakoti A, Amatya $R$, et. al. Prevalence of intestinal worm infestations among school children in Kathmandu, Nepal. Nepal Med Coll J 2011;13(4): 272-274

16. Tiwari BR, Chaudhary DR, Adhikari N, Jayaswal SK, Poudel $T P$, Rijal KR. Prevalence of Intestinal Parasitic Infections 
among School Children of Dadeldhura District, Nepal. JHAS 2013; 3(1): 14-16.

17. Taheri F, Namakin K, Zarban A, Shantzadesh G. Intestinal parastitc infection among school children in south khorasan province, Iran. JRes Health Sci 2011; 11: 45-50.

18. Rai K, Sherchand JB, Bhatta DR. Study of enteropathogens and its predisposing factors in gastroenteritis suspected children attending Kanti children Hospital, Kathmandu, Nepal. J Nepal Assoc Med Lab Sci 2004; 6: 48-53.

19. Sherchand PS, Joshi RD, Adhikari N, Gurung K, Pant K, Pun R et al. Intestinal parasitosis among school going children. JHAS 2010;1(1):12-15.

20. Ishiyama S, Rai SK, Ono K, Uga S. Small scale study on intestinal parasitosis in a remote hilly village in Nepal. Nepal Med Coll J 2003; 5: 28-30.

21. Bhandari N, Kausaph V, Neupane GP. Intestinal Parasitic Infection among School Age Children. J Nepal Health Res Counc 2011;9(18): 30-32.
22. Amara B, Ali J, Moges B, Yismaw G, Belyhun Y, Gebretsadik S et al. Nutritional status, intestinal parasite infection and allergy among school children in Northwest Ethiopia. BMC Pediatrics 2013, 13:7.

23. Shrestha A, Narayan KC, Sharma R. Prevalence of Intestinal Parasitosis Among School Children in Baglung District of Western Nepal. Kathmandu Univ Med J 2012; 10(37): 3-6.

24. Faraj AM, Koyee QMK. A Coprological Diagnostic Comparison Between Zinc Sulphate Floatation and Formalin:Ether Sedimentation with Two Natural Extracts (Pomegranate Molasses and Honey). Diyala Journal of Medicine 2011;1(2): 83-89.

25. Quihui-CL, Valenica ME, Crompton DWT, Phillips S, Hagen $P$, Diaz-C SP, et al. Prevalence and intensity of intestinal parasitic infections in relation to nutritional status in Mexican school children. Trans R Soc Trop Med Hyg 2004; 98:653659. Crompton DWT, Nesheim MC. Nutritional impact of intestinal helminthiasis during the human life cycle. Annu Rev Nutr 2002; 22: 3559. 